\title{
Exploring Factors Affecting on Willingness to Observe Air Pollution Reduction Policies in Tehran, Iran
}

\author{
${ }^{1}$ Pejman Jafari and ${ }^{2}$ Afrooz Botshekan \\ ${ }^{1}$ Department of Business Management, Science and Research Branch, Islamic Azad University, Tehran, Iran \\ ${ }^{2}$ Islamic Azad University, Science and Research Branch, Tehran, Iran
}

\author{
Article history \\ Received: 01-08-2020 \\ Revised: 03-11-2020 \\ Accepted: 25-02-2021 \\ Corresponding Author: \\ Afrooz Botshekan \\ Islamic Azad University, \\ Science and Research Branch, \\ Tehran, Iran \\ Email: Afrooz.Botshekan@gmail.com
}

\begin{abstract}
One of the most important issues of these days is an environmental pollution. Environmental problems such as air pollution and climate changes in urban areas are the results of human behavior. Only change in human behavior can reduce these environmental problems. Thus, studying attitude and behavior of people is a precondition to change this situation. This study aimed to examine relationships between personal factors, attitude, knowledge and people's environmental behavior. This research has been carried out in the social marketing framework and focused on air pollution reduction policies in Tehran. The method of collecting research data was a questionnaire. Questionnaires were distributed randomly among Tehran citizens and data were analyzed by SPSS software, factor analysis and linear regression analysis. It is emerged from the present study that marital status, having alive grandparents, education, gender, family member with the specific disease, the way of spending free time (inside or outside), traveling abroad, occupational status, having regular exercise programs as well as two variables of attitude and awareness of air pollution consequences, were identified as the most effective factors on willingness to observe air pollution reduction policies. Results of this study showed that citizens' priority to implement air pollution policies is paying city tax. This research also suggested that air pollution policies need to be addressed more rigorously for the targeted population. All these together can influence on people's behavior to reduce air pollution.
\end{abstract}

Keywords: Social Marketing, Air Pollution Policy, Environmental Behavior, Tehran

\section{Introduction}

Environmental problems and changes in living conditions have become a fundamental part of the world in general and metropolises in particular. Air pollution has become a persistent concern among large cities in developing countries over the past several decades (Wang et al., 2015). This will be a particular concern if citizens do not see that their decisions and actions are parts of current ongoing environmental degradation problems (Digby, 2013). Earlier, environmental problems have been considered as technical and economic problems; while in the recent decades the social dimensions of environmental problems such as public attention towards environment have become one of the areas of environmental sociology and environmental psychology (Kalantari et al., 2007). These issues are also increasingly taking more attention of policy into account in Iran in the recent decades. Particularly, increasing population density in Tehran is putting more pressure on this city's environment and air pollution constitutes to the most serious environmental problems that threatens public health. Although projects such as petrol quotas, odd and even policy, LIZ policy, advertising plans and various educational teasers in various related fields are being implemented and expanded, air pollution is still one of the most significant environmental problems in Tehran. The study of air quality in 2018 in Tehran showed that this year has included 28 days of clean air, 278 days of healthy air and 59 days of unhealthy air for sensitive groups (TAQCCOS, 2018).

Therefore, investigating environmental behavior of Tehran residents is a major concern of this paper. In this study, the effects of demographic factors, attitude and awareness on Tehran citizens' willingness to observe air pollution reduction policies have been explored with the Regression method. We hypothesized that demographic factors, attitude and awareness affect the willingness of Tehran citizens to observe air pollution reduction policies. If there are any differences in the impact of these factors, we will conclude that the willingness to observe air 
pollution reduction policies is different for different population groups and for each of these groups, different programs must be implemented. The findings from this research may help to provide some practical advice for the government to improve the environmental policies in Tehran and also can be applied in other developing countries.

\section{Conceptual Framework}

Kotler and Zaltman (1971) first coined the term of social marketing to describe an expanded role of marketing practice in the business of an idea and behavioral changes. Changes require the presumption that the current behavior can be replaced with a more beneficial set of activities that will lead to positive societal outcomes. In social marketing, earning personal profit is not a top priority (Dann, 2010). Kotler and Lee (2008) defined social marketing as a "process that applies marketing principles and techniques to create, communicate and deliver value to influence citizen behaviors that benefit society (public health, safety, environment and communities)". Social marketing is "the systematic application of marketing concepts and techniques to achieve specific behavioral goals" (Dann, 2010). The concept of the social goal is connected to the creation or prevention of observable and measurable behavior within the targeted population (Dann, 2010).

Several studies have investigated the relationship between knowledge, attitude and behavior (Digby, 2013). Coyle (2005) reported that environmentally knowledgeable people are $10 \%$ more likely to save energy at home and $50 \%$ more likely to recycle. Digby (2013) found that age, gender, education, income, Knowledge effect on people's attitudes towards environmental aspects.

In some other researches, results vary regarding the relationship between education and environmental behavior. A survey in Kentucky indicated that environmental attitude is not significantly different in various educational levels (KEEC, 2005); however, Digby (2013) and Torres (2016) reported that education affects environmental behaviors.

Wang et al. (2015) asserted that income and education influence people's willingness to pay to reduce air pollution in Shanghai, China.

A study by Torres (2016) in the Philippines found that people believe that they are affected by air pollution that threatens their health and they want to spend money to improve air quality. In this study, gender, age, education and income had significant impact on people's attitudes towards environmental aspects. From people point of view, the news media was an important source of health information.

Ghorbani (2011) has studied about the economic value of healthy air and the factors that effect on people's willingness to pay for reducing air pollution in Mashhad,
Iran. The results showed that the variables of education, age, area of residence, gender and having children are effective factors in paying for reducing air pollution.

A review of this literature revealed that most approaches identify environmental attitude and behavior as multi-dimensional phenomena and very few of these studies focused on citizen behavior in air pollution reduction policies and did not address the role of some variables such as having alive grandparents, traveling abroad, having regular exercise programs, the way of spending leisure time (outdoors or indoors) as possible predictors in environmental behavior. This study intends to close this knowledge gap by adding these factors to the proposed model.

To examine relationship between individual characteristics, environmental attitude, environmental knowledge and environmental behavior, a conceptual framework was derived from reviewed literature and the questionnaire was developed based on that.

\section{Materials and Methods}

\section{Study Site}

Investigating environmental behavior of Tehran residents towards air pollution reduction policies is a major concern of this paper. Tehran is a rapidly developing city in Iran as well as one of the most polluted cities of this country. Tehran is the capital of Iran and has a population of over 8 million.

\section{Sampling and Data Collection}

The present study was based on a survey field and sampling method was random clustering. Due to the need for sampling from different parts of Tehran, this city was divided into five clusters of north, south, east, west and center and random sampling was performed in each of these areas. The research population of the study was all Tehran residents aging over 16 years old. Based on Cochran formulate, total sample size of 400 was estimated. A questionnaire was used for data collection and the survey worked out through face-to-face interview at local places in each area such as parks, malls and metro station. Surveys were collected between April and May 2017.

To examine the reliability of the questionnaire a pilot study was conducted on 30 residents and Cronbach's Alpha of Likert-type scales were calculated by SPSS software. The results $(\alpha=0.738)$ showed that internal consistency among the questionnaire items was appropriate.

The first part of the survey contains demographic questions including gender, marital status, area of residence, age, education, employment status, average monthly income, vehicle to go to work, having children, having alive grandparents, having a family member with a specific disease, traveling abroad, having exercise program, reading newspapers or news sites, bedtime and 
the way of spending free time (inside or outside). The second section measures attitude towards observing air pollution reduction policies containing 10 Likert-type questions. The third section asked about environmental awareness that were related to the popular environmental topics and average citizens were expected to be familiar with them. The final section is about willingness to observe air pollution reduction policies including 11 Likert-type questions.

At the end of the questionnaire, respondents were asked to rank air pollution reduction policies as they wish, including increasing petrol price, paying city tax and implementing traffic plans.

\section{Statistical Analysis}

First, for analyzing the effect of demographic characteristics on the dependent variable (willingness to observe air pollution reduction policies) regression method in SPSS is used. Questions with the Likert scale in the questionnaire, that include attitude and willingness to observe air pollution reduction policies, are classified by the exploratory factor analysis method in Amos software and then by the confirmatory factor analysis method, these classifications will be confirmed (Questions have been classified into two groups: Attitude and willingness). It should be noted that the questions in the awareness section do not need to be explored and verified because they have two aspects, zero and one (zero: Wrong answer and one: Correct answer).

After confirming this classification, the effect of the independent factors (attitude and awareness) on the dependent factor (willingness to observe air pollution reduction policies) is measured and analyzed by using Analysis Of Variance technique (ANOVA), Fisher test and regression method. All statistical procedures are conducted using SPSS software.

Finally, the results of multi-choice questions about ranking air pollution reduction policies analyze by Kruskal-Wallis test in SPSS software.

In this study, we aimed to have two regression equations that the first one is related to the effect of demographic variables on willingness to observe air pollution reduction policies and the second is related to the effect of attitude and awareness on willingness to observe air pollution reduction policies. below:

Regression linear can be defined for this survey as

- Willingness to observe air pollution reduction policies $=\sum \beta_{\mathrm{i}} * \mathrm{X}_{\mathrm{i}}+\alpha$

$\left(\mathrm{X}_{\mathrm{i}}=\right.$ different demographic characteristics)

- Willingness to observe air pollution reduction policies $=\beta_{1} *\left(X_{1}\right)+\beta_{2} *\left(X_{2}\right)+\alpha$

$X_{1}=$ Attitude

$$
\begin{aligned}
& X_{2}=\text { Awareness } \\
& (\alpha \text { : Intersection point of the regression line with the } \\
& \text { Y-axis })
\end{aligned}
$$

\section{Results}

\section{Demographic Variables Assessment}

Table 1 presents the independent variables of the respondents including demographic characteristics. In the present study 400 people were interviewed in Tehran, out of whom $22 \%$ lived in the north, $20 \%$ in the center, $18 \%$ in east, $22 \%$ in west and $18 \%$ in the southern part of Tehran. Out of them, $41 \%$ of respondents were Single, $59 \%$ married, $55 \%$ were female and $45 \%$ were male. In terms of age structure, about $10 \%$ of them were under $28,40 \%$ in $29-42$ age, $24 \%$ in $43-61$ age and $26 \%$ older than 62 (Age group based on Smith and Clurman, 1997). $23 \%$ of respondents had received secondary and college certificate, $40 \%$ of them had Bachelor degree and $26 \%$ had received higher education certificates, including MSc and Ph.D. This table also shows status of respondent occupation. As we will note later, occupation is one of the factors that influence respondents' environmental behavior. According to this table more than $15 \%$ of the respondents were housewives and $49 \%$ were clerks. About $27 \%$ of them were freelancers and only $9 \%$ were jobless. Income is also a crucial factor in explaining environmental behavior. The income level of the respondents is shown in Table 1. As it is depicted from this table, $24 \%$ of the respondents do not earn any income because they are jobless, housewives or students. About $8 \%$ had income less than 8,000,000 Rls while $32 \%$ had income more than 25,000,000 Rls. per month.

The correlation coefficient $(\mathrm{R})$ shows the correlation between demographic variables and Willingness to observe air pollution reduction policies, which is 0.663 . The coefficient of determination $\left(\mathrm{R}^{2}\right)$ also shows how much of the dependent variable can be explained by independent variables. This coefficient is 0.44 , which means that $44 \%$ of the changes in the willingness to observe air pollution reduction policies are predicted by the population variables.

F statistical test (Fisher coefficient) has been used for testing the significance of the regression model. Fisher coefficient and corresponding probability level were statistically significant $(\mathrm{F}=5.41$ and $\mathrm{Sig}=0.0<0.05)$. Therefore, there is a regression line in this analysis and we conclude that independent variables are appropriate predictors for the dependent variable. According to the results of the initial regression model in SPSS software, demographic factors have different coefficients in the regression equation (Table 2 ). 
The factors that t-statistics are more than 1.96 and their significance levels (Sig.) are less than 0.05 have statistically significant correlation with dependent variable. Other factors must be omitted step by step by
Backward removal method in SPSS software. This operation is repeated to keep the maximum number of semantic factors. The results of the last step are shown in Table 3.

Table1: Descriptions of independent variables

\begin{tabular}{|c|c|c|c|}
\hline Categorical variables & Description & Percentage $\%$ & No. \\
\hline \multirow[t]{2}{*}{ Gender } & Male & 45 & 176 \\
\hline & Female & 55 & 214 \\
\hline \multirow[t]{2}{*}{ Marital status } & Single & 41 & 161 \\
\hline & Married & 59 & 229 \\
\hline \multirow[t]{5}{*}{ Area of residence } & North & 22 & 87 \\
\hline & South & 18 & 72 \\
\hline & East & 18 & 72 \\
\hline & West & 22 & 82 \\
\hline & Center & 20 & 77 \\
\hline Age & $28>$ & 10 & 42 \\
\hline (Age group based on Smith and & $29-42$ & 40 & 158 \\
\hline \multirow[t]{2}{*}{ Clurman, 1997) } & $43-61$ & 24 & 90 \\
\hline & $62<$ & 26 & 100 \\
\hline \multirow[t]{4}{*}{ Education } & Secondary school & 15 & 58 \\
\hline & College & 18 & 72 \\
\hline & Bachelor & 40 & 155 \\
\hline & Master's degree and Ph.D. & 26 & 105 \\
\hline \multirow[t]{4}{*}{ Job status } & Clerk & 49 & 186 \\
\hline & Freelancer & 27 & 105 \\
\hline & Housewife & 15 & 61 \\
\hline & Jobless & 9 & 38 \\
\hline Income & 0 & 24 & 93 \\
\hline \multirow[t]{4}{*}{ (Unit: Rial $10^{3}$ ) } & $<8000$ & 8 & 35 \\
\hline & $8000-15000$ & 16 & 62 \\
\hline & $15000-25000$ & 20 & 77 \\
\hline & $>25000$ & 32 & 124 \\
\hline \multirow[t]{7}{*}{ Vehicle to go to work } & Private vehicle & 35 & 102 \\
\hline & Private motor cycle & 7 & 21 \\
\hline & Public transportation & 31 & 89 \\
\hline & Walk & 8 & 23 \\
\hline & Private vehicle and walk & 6 & 16 \\
\hline & Private vehicle and Public transportation & 5 & 14 \\
\hline & Public transportation and walk & 8 & 22 \\
\hline \multirow[t]{2}{*}{ Having a child } & Yes & 38 & 149 \\
\hline & No & 62 & 241 \\
\hline \multirow[t]{2}{*}{ Having alive grandparents } & Yes & 42 & 166 \\
\hline & No & 58 & 224 \\
\hline \multirow[t]{2}{*}{ Family member with a specific disease } & Yes & 22 & 88 \\
\hline & No & 78 & 302 \\
\hline \multirow[t]{2}{*}{ Traveling abroad } & Yes & 69 & 267 \\
\hline & No & 31 & 123 \\
\hline \multirow[t]{2}{*}{ Having regular exercise programs } & Yes & 31 & 121 \\
\hline & No & 69 & 269 \\
\hline \multirow[t]{3}{*}{ Reading newspaper or news sites } & $<$ half an hour & 31 & 121 \\
\hline & half an hour-an hour & 69 & 269 \\
\hline & $>$ an hour & 27 & 105 \\
\hline \multirow[t]{3}{*}{ Sleep hours } & $<7 \mathrm{~h}$ & 50 & 196 \\
\hline & $7-9 \mathrm{~h}$ & 45 & 174 \\
\hline & $>9 \mathrm{~h}$ & 5 & 20 \\
\hline \multirow[t]{2}{*}{ How to spend free time } & At home & 59 & 228 \\
\hline & Out of home & 41 & 162 \\
\hline
\end{tabular}


Table 2: Initial regression coefficients

\begin{tabular}{|c|c|c|c|c|c|c|}
\hline Item & Categorical variables & B unstandardized & Standardized coefficients beta & Std. Error & $\mathrm{t}$ & Sig. \\
\hline 1 & Constant & -2.953 & 1.933 & & -1.528 & 0.129 \\
\hline 2 & Gender & -0.479 & 0.215 & -0.192 & -2.233 & 0.027 \\
\hline 3 & Marital status & 1.075 & 0.248 & 0.429 & 4.335 & 0.000 \\
\hline 5 & Age & -0.137 & 0.261 & -0.070 & -0.523 & 0.602 \\
\hline 6 & Education & 0.630 & 0.280 & 0.305 & 2.249 & 0.026 \\
\hline 7 & Job status & -0.558 & 0.172 & -0.439 & -3.254 & 0.001 \\
\hline 8 & income & -0.104 & 0.109 & -0.122 & -0.953 & 0.343 \\
\hline 9 & Vehicle to go to work & 0.074 & 0.066 & 0.098 & 1.123 & 0.264 \\
\hline 10 & Having a child & -0.212 & 0.336 & -0.074 & -0.630 & 0.530 \\
\hline 11 & Alive grandparents & 0.607 & 0.245 & 0.240 & 2.473 & 0.015 \\
\hline 12 & Family member with the specific disease & -0.601 & 0.299 & -0.181 & -2.010 & 0.047 \\
\hline 13 & Traveling abroad & 0.174 & 0.281 & 0.060 & 0.620 & 0.537 \\
\hline 14 & Exercise & 0.283 & 0.409 & 0.065 & 0.693 & 0.490 \\
\hline 15 & Having regular exercise programs & 0.414 & 0.175 & 0.207 & 2.366 & 0.020 \\
\hline 16 & Reading newspaper or news sites & -0.075 & 0.142 & -0.044 & -0.529 & 0.598 \\
\hline 18 & How to spend free time & 0.431 & 0.215 & 0.172 & 2.004 & 0.047 \\
\hline
\end{tabular}

Table 3: Final regression coefficients of the last step of the Backward removal method

\begin{tabular}{|c|c|c|c|c|c|c|}
\hline Item & Categorical variables & B unstandardized & $\begin{array}{l}\text { Standardized } \\
\text { coefficients beta }\end{array}$ & Std. Error & $\mathrm{t}$ & Sig. \\
\hline 1 & Constant & -3.871 & 1.454 & & -2.662 & 0.009 \\
\hline 2 & Gender & -0.597 & 0.223 & -0.237 & -2.678 & 0.009 \\
\hline 3 & Marital status & 0.930 & 0.234 & 0.369 & 3.972 & 0.000 \\
\hline 4 & Education & 0.636 & 0.205 & 0.295 & 3.110 & 0.002 \\
\hline 5 & Job status & -0.392 & 0.118 & -0.311 & -3.313 & 0.001 \\
\hline 6 & Alive grandparents & 0.828 & 0.219 & 0.327 & 3.776 & 0.000 \\
\hline 7 & Family member with the specific disease & -0.578 & 0.307 & -0.175 & -2.883 & 0.006 \\
\hline 8 & Traveling abroad & 0.413 & 0.236 & 0.143 & 1.754 & 0.053 \\
\hline 9 & Having regular exercise programs & 0.333 & 0.161 & 0.167 & 2.067 & 0.041 \\
\hline 10 & How to spend free time (inside or outside) & 0.464 & 0.228 & 0.184 & 2.035 & 0.045 \\
\hline
\end{tabular}

We use unstandardized $B$ to create regression equation. The first generalized linear model is used to determine the combined influence of the demographic variables on willingness to observe air pollution reduction policies:

$$
\begin{aligned}
& Y=-3.871-0.597 * X_{1}+0.930 * X_{2}+0.636 * X_{3}-0.392 * X_{4} \\
& +0.828 * X_{5}-0.578 * X_{6}+0.413 * X_{7}+0.333 * X_{8}+0.464 * X_{9}
\end{aligned}
$$

$Y=$ The predicted value of the dependent variable (willingness to observe air pollution reduction policies)

$X_{i}=$ Different values of independent variables (population variables) including

$X_{1}=$ Gender

$X_{2}=$ Marital status

$X_{3}=$ Education

$X_{4}=$ Job status

$X_{5}=$ Having alive grandparents

$X_{6}=$ Having family member with a specific illness

$X_{7}=$ Travel Abroad

$X_{8}=$ Having regular exercise programs
$X_{9}=$ How to spend free time (insides or outsides)

\section{Attitude and Knowledge Variables Assessment}

All questions with the Likert-type scale, which include attitude and willingness questions, are categorized by exploratory factor analysis method and then this classification is confirmed by the confirmatory factor analysis method.

\section{Exploratory Factor Analysis}

Firstly, KMO and Bartlett tests have been performed (Table 4).

According to the amount of KMO $(0.723>0.7)$ and Bartlett test which is statistically significant ( $\mathrm{Sig}$ $<0.05$ ), it can be concluded that correlations between data are suitable for factor analysis. After rotating factors by Varimax method, questions were categorized into two groups, questions in the first category measure people's attitude and the second category measures people's willingness to observe air pollution reduction policies (Table 5). In the next step, this classification will be examined in Amos software with a confirmatory factor analysis technique. 


\section{Confirmatory Factor Analysis}

After exploring these two factors, they should be confirmed by using the Confirmatory Factor Analysis method in Amos software.

\section{Attitude}

There are specific measures that can be calculated to determine the goodness of fit. As can be seen in Table 7, the goodness indicators of fit and adequacy of the model are acceptable and indicate that these questions correctly measure attitude factor (Table 7).

\section{Willingness}

As can be seen in Table 9, the goodness indicators of fit and adequacy of the model are acceptable and indicate that these questions correctly measure willingness to observe air pollution reduction policies.

\section{Linear Regression}

The correlation coefficient $(\mathrm{R})$ shows the correlation between the variables of attitude, awareness and willingness to observe air pollution reduction policies, which is about 0.459 and the determination coefficient $\left(\mathrm{R}^{2}\right.$ $=0.211$ ) also shows how much of the dependent variable can be explained by the independent variables, which means that $21.1 \%$ of the changes in the willingness to observe air pollution reduction policies are predicted by the variables of awareness and attitude.

For testing the significance of the regression model, $\mathrm{F}$ statistical test (Fisher coefficient) has been used. Fisher coefficient and corresponding probability level were statistically significant $(\mathrm{F}=51.603$ and $\mathrm{Sig}=$ $0.0<0.05)$. Therefore, there is a regression line in this analysis and we conclude that the independent variables are appropriate predictors of the dependent variable. We use unstandardized $B$ to create a regression equation (Table 10).

The second generalized linear model is used to determine the combined influence of attitude and awareness on willingness to observe air pollution reduction policies:

$Y=-0.119+0.451 * X_{1}+0.181 * X_{2}$

$Y=$ The predicted value of the dependent variable (willingness to observe air pollution reduction policies)

$X_{1}=$ Attitude

$X_{2}=$ Awareness

Table 4: KMO and Bartlett test

\begin{tabular}{ll}
\hline 0.723 & KMO \\
\hline 1424.955 & Chi square \\
0 & Sig \\
\hline
\end{tabular}

Table 5: Rotated component matrix

\begin{tabular}{lll}
\hline Component & & Questions \\
\hline 2 & 1.000 & \\
0.47 & & Attitude 1 \\
0.721 & & Attitude 2 \\
0.576 & & Attitude 3 \\
0.716 & & Attitude 4 \\
0.667 & & Attitude 5 \\
0.311 & 0.020 & Attitude 6 \\
0.342 & & Attitude 7 \\
0.399 & & Attitude 8 \\
0.353 & 0.397 & Attitude 9 \\
& 0.751 & Willingness 1 \\
& 0.789 & Willingness 2 \\
& 0.800 & Willingness 3 \\
& 0.460 & Willingness 4 \\
& & Willingness 5 \\
\hline
\end{tabular}

Table 6: $\mathrm{P}$ and C.R for attitude factor

\begin{tabular}{llr}
\hline C.R & $\mathrm{P}$ & Questions \\
\hline 2.895 & $* * *$ & Attitude 1 \\
2.094 & $* * *$ & Attitude 2 \\
2.936 & $* * *$ & Attitude 3 \\
2.748 & $* * *$ & Attitude 4 \\
2.848 & $* * *$ & Attitude 5 \\
2.71 & $* * *$ & Attitude 6 \\
1.902 & $* * *$ & Attitude 7 \\
1.831 & $* * *$ & Attitude 8 \\
1.96 & $* * *$ & Attitude 9 \\
\hline$* * *$ Indicates the number 0.000, which is less than 0.05 and \\
means that the model is significant (Table 6)
\end{tabular}

Table 7: Attitude model adequacy index

\begin{tabular}{llr}
\hline Measures of Fit & Acceptable amount & \multicolumn{1}{c}{ Result } \\
\hline$X_{2}$ & & 102.599 \\
DF & $>0$ & 35.000 \\
$x^{2} /$ df & $<3$ & 2.930 \\
RMSEA & $<0.08$ & 0.078 \\
CFI & $>0.90$ & 0.928 \\
NFI & $>0.90$ & 0.986 \\
\hline
\end{tabular}

Table 8: $\mathrm{P}$ and C.R for willingness factor

\begin{tabular}{lcl}
\hline C.R & $\mathrm{P}$ & Questions \\
\hline 3.824 & $* * *$ & Willingness 1 \\
5.783 & $* * *$ & Willingness 2 \\
6.151 & $* * *$ & Willingness 3 \\
6.158 & $* * *$ & Willingness 4 \\
6.153 & $* * *$ & Willingness 5 \\
\hline$* * *$ Indicates the number 0.000, which is less than 0.05 and \\
\multicolumn{2}{l}{ means that the model is significant (Table 8) }
\end{tabular}

Table 9: Willingness model adequacy index

\begin{tabular}{lrl}
\hline Acceptable amount & Result & Measures of fit \\
\hline & 17.121 & X2 \\
$>0$ & 6.000 & DF \\
$<3$ & 2.850 & $x^{2} / \mathrm{dt}$ \\
$<0.08$ & 0.061 & RMSEA \\
$>0.9$ & 0.923 & CFI \\
$>0.9$ & 0.913 & NFI \\
\hline
\end{tabular}


Table 10: Regression coefficients

\begin{tabular}{llllll}
\hline Categorical variables & B unstandardized & Standardized coefficients beta & Std. error & $\mathrm{t}$ & Sig. \\
\hline Constant & -0.119 & & 0.077 & 1.54 & 0.000 \\
Attitude & 0.451 & 0.451 & 0.045 & 9.984 & 0.000 \\
awareness & 0.181 & 0.086 & 0.095 & 1.901 & 0.058 \\
\hline
\end{tabular}

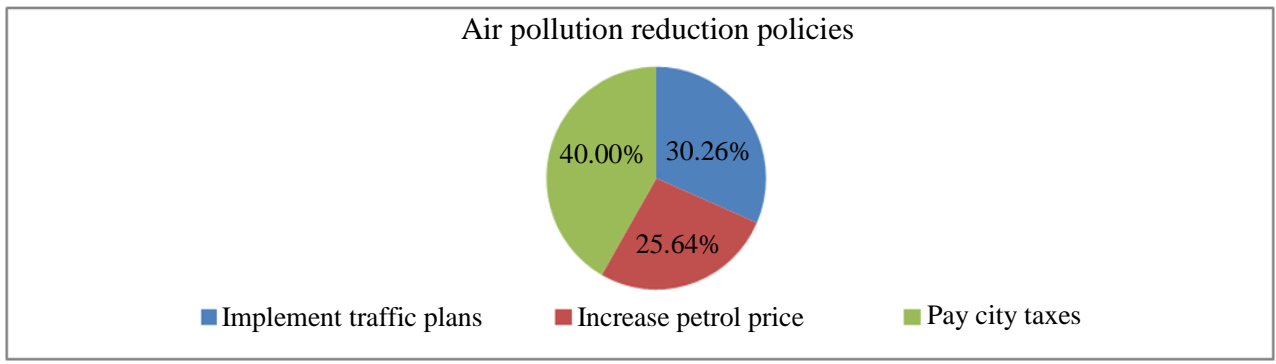

Fig. 1: ranking air pollution reduction policies

\section{Discussion}

One of the ways to test the validity of the research results is to compare with other related studies outcomes (Wang et al., 2015). Table 3 indicates that willingness to observe air pollution reduction policies in Tehran citizens is highly influenced by two important variables of marital status (0.093) and having alive grandparents (0.828). This result is consistent with related studies that have been carried out before in Iran (Ghaderi et al., 2015), While education (0.636) is next to these factors. There were several studies suggesting that education plays an important role in enhancing the environmental behavior (Torres, 2016; Ghorbani, 2011; Wang et al., 2015).

Gender and willingness to observe air pollution reduction policies have statistically significant relationship (0.597). Previous studies have got the same results in Mashhad in Iran (Ghorbani, 2011) and in Philippine (Torres, 2016) which can also prove the validity of this study.

It is also depicted from Table 3 that having a family member with specific disease (0.578) influence willingness to observe air pollution reduction policies and it can be used to test the validity of this study with comparing with similar researches: This result is consistent with the study in Shanghai in china (Wang et al., 2015).

Job status (0.392) was another factor that effect on environmental behavior. This result is consistent with Ghadery research in 2013.

The empirical results deriving from the data set show that the attitude of Tehran citizens towards air pollution (0.451) affects their willingness to observe air pollution reduction policies. These relationships were proved by number of studies worked out by Yazdanparast et al. (2013) in Iran and Torres (2016) in Philippine. Also, awareness (0.181) of Tehran citizens about air pollution affects their willingness to observe air pollution reduction policies. This result has been consistent with related studies carried in Iran (Kalantari et al., 2007).

In the questionnaire, respondents were asked to rank air pollution reduction policies (including increasing the price of petrol, paying city tax and implementing traffic plans). Results are shown in Fig. 1. Regarding respondents' answers to multiple-choice questions, 39\% of citizens believe that the best way to increase people collaboration in reducing air pollution was education. Most citizens (90\%) consider paying fines as the main reason for applying technical examination for their cars and $75 \%$ of the citizens believe that developing public transportation is an effective way to reduce air pollution. Most citizens ( $87 \%$ ) consider air pollution as the priority of pollution and this shows the importance of this issue for Tehran residents.

\section{Conclusion}

The findings of the present study showed that marital status and having alive grandparents affect Tehran citizens' willingness to observe air pollution reduction policies. Also, education plays an important role in enhancing the environmental behavior. Gender and job status are other effective factors. Therefore, air pollution planners and policymakers are advised to pay more attention to the gender factor and take advantage of the emotional and psychological differences between men and women to increase the impact of their environmental advertising programs and also, different programs and incentives must be implemented for different job groups.

Deriving from the data set, having a family member with specific disease and having a regular exercise program effect on willingness to observe air pollution 
reduction policies which shows that by increasing citizens' awareness about the effects of pollution on health, citizens' willingness to observe air pollution reduction policies can be increased.

The empirical results show that people's attitude and awareness have a significant relationship with willingness to observe air pollution reduction policies; It can be concluded that citizens' attitudes should be considered in air pollution reduction planning and policies and by increasing the level of environmental awareness of citizens through the media and also about other countries environmental policies and obtained results especially in developed countries, citizens' willingness to observe air pollution reduction policies can be increased.

Overall, in this study, results indicate that it may be necessary to program different strategies with different populations, that can also lead to more influential changes in residents' behavior towards air pollution policies particularly with the help of environmental legislation. All these can change people's behavior to preserve the environment.

These results can serve as a reference to track public behavior in other aspects of environmental pollution such as water and soil in the future and also numerous variables can be added and developed to investigate people's environmental behavior according to the specific circumstances.

\section{Acknowledgement}

Authors would like to thank Dr. Farhad Ghaffari Associate Professor of Islamic Azad University, Science and Research Branch for his coordination and assistance in this study.

\section{Author's Contributions}

All authors contributed equally in this paper.

\section{Ethics}

Authors ensure that they have written entirely original work and this study contains unpublished materials. The corresponding author confirms that all other authors have read and approved the manuscript and no ethical issues have been involved.

\section{References}

KEEC. (2005). The 2004 Survey of Kentuckians' environmental knowledge, attitudes and behaviors. http://Educationcabinet.ky.gov/newsroom/press releases/KEEC survey.htm

Coyle, K. (2005). Environmental literacy in America: What ten years of NEETF/Roper research and related studies say about environmental literacy in the US. National Environmental Education \& Training Foundation. http://www.neetf.Org/pubs/ELR2055.pdf
Dann, S. (2010). Redefining social marketing with contemporary commercial marketing definitions. Journal of Business Research, 63(2), 147-153. https://www.sciencedirect.com/science/article/abs/pi i/S0148296309000319

Digby, C. L. (2013). The influences of socio-demographic factors and non-formal and informal learning participation on adult environmental behaviors. International Electronic Journal of Environmental Education, 3(1), 37-55.

Ghaderi, N., Choupani, S., \& Salehi, S. (2015). A Study of social factors affecting on environmental attitudes and behavior in the Marivan city in 2014. Zanko Journal of Medical Sciences, 16(48), 10-18. http://zanko.muk.ac.ir/article-1-58-en.html

Ghorbani, M., (2011). Investigation of Citizens' WTP for Mashhad Air Pollution Reduction: Applying Heckit model, Ferdowsi University of Mashhad, Iran. https://www.sid.ir/en/Journal/ViewPaper.aspx?ID=2 74308.

Kalantari, K., Fami, H. S., Asadi, A., \& Mohammadi, H. M. (2007). Investigating factors affecting environmental behavior of urban residents: A case study in Tehran City-Iran. American Journal of Environmental Sciences, 3(2), 67-74. https://www.inderscience.com/inorders/bkpage.php? rec_id=371\&journalID=1008\&chapNum =5

Kotler, P., \& Lee, N. (2008). Social marketing: Influencing behaviors for good. Sage.

Kotler, P., \& Zaltman, G. (1971). Social marketing: an approach to planned social change. Journal of Marketing, 35(3), 3-12. https://journals.sagepub.com/doi/abs/10.1177/00222 4297103500302

Smith, J. W., \& Clurman, A. (1997). Rocking the ages: The Yankelovich report on generational marketing. New York: HarperBusiness. ISBN-10: 0887308139.

TAQCCOS. (2018). Tehran Air Quality Control Corporation Official Site. https://air.tehran.ir/portals/0/ReportFiles/AirPollutio n/Tehran\%20AirQuality1395.pdf

Torres, E., (2016). Environmental health: past, present and future, College of Public Health University of Philippines, Manila.

Wang, K., Wu, J., Wang, R., Yang, Y., Chen, R., Maddock, J. E., \& Lu, Y. (2015). Analysis of residents' willingness to pay to reduce air pollution to improve children's health in community and hospital settings in Shanghai, China. Science of the Total Environment, 533, 283-289. https://www.sciencedirect.com/science/article/abs/pi i/S004896971530317X 
Yazdanparast, T., Salehpour, S., Masjedi, M. R., Azin, S. A., Seyedmehdi, S. M., Boyes, E., ... \& Attarchi, M. (2013). Air pollution: the knowledge and ideas of students in Tehran-Iran and a comparison with other countries. Acta Medica Iranica, 487-493. https://acta.tums.ac.ir/index.php/acta/article/view/4406

\section{High Lights}

- The effects of demographic factors, attitude and awareness on Tehran residents' willingness to observe air pollution reduction policies have been investigated.

- Exploratory factor analysis and confirmatory factor analysis methods in Amos software was used for categorizing questions.
- The regression method was used to measure the effects of independent variables on the dependent variable.

- This study concludes that marital status, having alive grandparents, education, gender, family member with the specific disease are important predictors of Tehran citizens' willingness to observe air pollution reduction policies.

- Respondents' willingness to observe different air pollution reduction policies is as bellow:

First paying city taxes, second implement traffic plans and the third increase petrol price. 